\title{
O ENSINO DA TEORIA SOCIOLÓGICA
}

\section{TEACHING SOCIOLOGICAL THEORY}

\author{
Rui Pena Pires \\ Departamento de Sociologia, Escola de Sociologia e Políticas Públicas, Iscte - Instituto Universitário de Lisboa \\ \& Centro de Investigação de Estudos de Sociologia CIES-Iscte, 1649-026 Lisboa, Portugal. \\ Email: rpenapires@gmail.com
}

\begin{abstract}
Resumo: O ensino da teoria sociológica assemelha-se ao ensino de um cânone. Retomando debates antigos lançados por Merton, argumenta-se neste artigo em favor do abandono da forma canónica de ensino da teoria sociológica e propõe-se a sua substituição pela criação de três disciplinas sobre a "sistemática atual" da teoria sociológica: uma disciplina de microssociologia, outra de macrossociologia e uma terceira de mesossociologia. Por fim, argumenta-se que o estudo dos clássicos, fundadores e contemporâneos, deve fazer-se nos níveis pós-graduados de mestrado e doutoramento, depois do estudo da sistemática da teoria na licenciatura. É ainda apresentada uma proposta preliminar sobre possíveis linhas programáticas gerais das cadeiras de micro, macro e meso sociologia.
\end{abstract}

Palavras-chave: teorias sociológicas, ensino da sociologia.

\begin{abstract}
The teaching of sociological theory resembles the teaching of a canon. Resuming old debates launched by Merton, this paper argues for abandoning the canonical form of the teaching of sociological theory and proposes its replacement by the creation of three courses on the "current systematics" of sociological theory: a course on microsociology, another on macrosociology and a third on mesosociology. Finally, it is argued that the sociological classics, founders and contemporaries, should be studied at postgraduate masters and doctoral levels, after going over the systematics of sociological theory in undergraduate studies. It is also presented a preliminary proposal of the main themes for the syllabus of the micro, macro and meso sociology courses.
\end{abstract}

Keywords: sociological theory, teaching sociology.

Como ensinar teoria sociológica? A pergunta tem uma história já longa na sociologia e interpela, ou devia interpelar, quem tem a obrigação de conceber, desenhar e aplicar programas de cadeiras com aquele objetivo, bem como planos de estudo de cursos nesta área. No Iscte, foi objeto de um simpósio organizado e participado por professores e estudantes no ano letivo 2017/18. ${ }^{1}$ Este texto começou a ganhar forma enquanto comunicação apresentada naquele simpósio e beneficiou dos debates então ocorridos. Na altura, como agora, é meu convencimento que predomina um modo errado e contraproducente de apresentar e ensinar a teoria sociológica, que se reproduz com facilidade por falta de questionamento fundamentado. ${ }^{2}$ Apresentam-se, a seguir, alguns argumentos para esse questionamento e uma proposta alternativa que pode ser resumida com a expressão mertoniana "substituir o ensino da história da teoria pelo ensino da sua sistemática atual". 


\section{História ou sistemática? Crítica da fórmula canónica}

O ensino da teoria sociológica, na generalidade das universidades portuguesas como nas europeias ou americanas, é o ensino de um cânone (Parker, 1997, pp. 125-6). Aos alunos são apresentados, em regra por ordem cronológica, os sociólogos que todos os sociólogos devem conhecer e por confronto com os quais serão avaliadas as suas realizações. Também, em regra, essa apresentação tende a ser desdobrada em duas disciplinas: uma sobre os autores clássicos, outra sobre os autores contemporâneos (Abrutyn, 2013, pp. 133-4).

A fixação do cânone é alvo de disputas. Em primeiro lugar, sobre a seleção dos autores a incluir e a excluir. Variável com o tempo e as oscilações reputacionais, a seleção é hoje desafiada pelas pressões para o reconhecimento de uma maior diversidade racial e de género entre os fundadores da disciplina, através, por exemplo, da inclusão entre os clássicos de William Edward Burghardt "W.E.B." Du Bois ou de Charlotte Perkins Gilman e Harriet Martineau (Abrutyn, 2013; Barbalet, 2013). A busca de maior diversidade prolonga-se ainda com a inclusão, entre os mais longínquos percursores da disciplina, de referências a autores não europeus e não americanos, como, por exemplo, Abdel Rahman Ibn-Khaldun, árabe, nascido em 1332 no que é hoje a Tunísia. ${ }^{3}$ No limite, a crítica ao cânone desemboca na proposta de um programa de ensino da teoria sociológica de orientação multicultural (Parker, 1997, p. 137). ${ }^{4}$

Uma segunda disputa no âmbito do cânone tem por objeto a atribuição do estatuto de "clássico". Há umas décadas, esse estatuto estava reservado ao trio Marx, Durkheim e Weber, eventualmente acompanhados por Spencer, Simmel ou Pareto. Com a explosão do número de autores e correntes a partir dos anos 60 do século XX, foram vários os manuais de referência a propor a extensão do período fundador da disciplina até à II Guerra Mundial para incluir autores como Parsons, Merton e Mead entre os clássicos, redefinindo a fronteira entre estes e os contemporâneos. ${ }^{5}$

Em rigor, trata-se de debates pouco interessantes e provavelmente infindáveis em que, para além do mais, está presente uma confusão entre o ensino da teoria social, o ensino da teoria sociológica e o ensino da sociologia. Mais importante, é o conjunto de pressupostos epistemológicos e pedagógicos implicados na opção pelo ensino das teorias sociológicas como o ensino de um cânone.

Como assinalava Merton já em 1947, aquela opção implica uma confusão entre teoria sociológica e história da sociologia que prejudica os dois programas: porque transforma a história da sociologia numa narrativa simplificada, mesmo caricatural, por um lado, e porque impede a constituição de processos de cumulatividade teórica que ampliem a teoria ao longo do tempo, por outro (Merton, 1968, cap. I). É 
conhecida a crítica de Alexander (1987) a esta avaliação de Merton, crítica que se desdobra em dois planos. Num primeiro plano, a crítica tem por objetivo a explicação das razões da fusão entre história e teoria no domínio da sociologia. Num segundo plano, a crítica desemboca numa justificação da utilidade funcional daquela fusão. Em síntese, Alexander parte de uma explicação, convincente, sobre as razões do que chama "sobredeterminação discursiva" da teoria sociológica, passa por uma controversa argumentação sobre a natureza endémica dessa sobredeterminação e conclui com a justificação funcional da "centralidade dos clássicos" na teoria sociológica.

O passo controverso da argumentação de Alexander consiste, sobretudo, no endosso que faz das teses de Mannheim sobre a "relação simbiótica entre descrição e avaliação" nas ciências sociais (Alexander, 1987, p. 21). Dada a simbiose, os conflitos ideológicos e normativos sobre o que o mundo deve ser tornariam endémicas as oposições entre escolas teóricas rivais constituídas na base de diferentes pressupostos no plano dos valores. Como já foi objeto de muitos debates, a começar pelas teses weberianas sobre a neutralidade axiológica, há nesta posição uma sequência demasiado linear que, começando com o argumento sobre a impossibilidade de subjetividades castradas de sentido normativo, passa, quase diretamente, para a conclusão de que é impossível, por isso, qualquer tipo de neutralidade axiológica no trabalho científico, ignorando, ou tratando em termos unilaterais, os efeitos das orientações normativas e condições relacionais que definem o papel social do cientista (Merton, 1968, caps. XV e XVIII). Ou seja, oscilando entre um reducionismo individualista, no qual o trabalho científico é tratado como exercício isolado subjetivamente orientado, e um reducionismo coletivista, em que a posição normativa do cientista social está pré-determinada pelo seu posicionamento estrutural. Nestas operações de redução desaparece a análise do trabalho científico, nas ciências sociais como nas ciências naturais, enquanto desempenho regulado de um papel socialmente construído e acionado em contextos situacionais de interação, e desaparecem também os efeitos lógicos autónomos dos textos sociais (neste caso o ethos da ciência), cujo estudo viria a constituir, décadas depois do artigo sobre a centralidade dos clássicos, o "programa forte" de Alexander para a sociologia cultural. Ora, se o trabalho científico é o desempenho regulado de um papel socialmente construído, culturalmente ancorado e acionado em contextos situacionais de interação, então a "fusão entre descrição e avaliação" não é uma característica essencial das ciências sociais mas uma possibilidade mais ou menos intensa e alargada do exercício da atividade científica, variável em função dos contextos sociais e culturais em que esse exercício é realizado.

Se Alexander insiste no problema da fusão entre descrição e avaliação para contestar a possibilidade de um programa forte da sociologia científica, nomeadamente 
no domínio da cumulatividade do conhecimento, não deixa de fazer referência a outros obstáculos àquele programa, destacados também por autores como Giddens (1989, p. 42): são eles, o problema da autonomia do indivíduo e consequente imprevisibilidade relativa dos atos individuais, por um lado, e os efeitos de dupla hermenêutica no exercício da reflexividade, por outro. Noutro texto (Pires, 2012), argumentei mais extensamente que, também nestes planos, estamos perante dinâmicas variáveis, por oposição a características essenciais da sociologia, concluindo que: (a) "num quadro relacional, isto é social, a imprevisibilidade dos atos individuais deve deixar de ser analisada enquanto atributo geral da ação humana e passar a ser estudada como propriedade variável e probabilística de atos concretos"; $\mathrm{e}(\mathrm{b})$ "afirmar que o conhecimento pode mudar o objeto do conhecimento não é o mesmo que afirmar que todo o conhecimento muda o objeto do conhecimento", pelo que "as relações entre conhecimento e mudança são variáveis e constituem objeto da análise sociológica" (Pires, 2012, pp. 35 e 39).

Trocando as armadilhas do essencialismo pelas virtualidades de uma perspetiva relacional, é possível, como muitos outros autores o têm feito, de Weber a Merton, de Collins a Turner, defender a viabilidade do programa da sociologia científica, com os respetivos corolários no domínio da teoria. E, nesse caso, a apresentação da teoria sociológica enquanto cânone deixará de ser uma característica incontornável da disciplina mas antes o resultado de uma opção predominante, mas controversa, no seu desenvolvimento e ensino.

A referida opção tem raízes antigas, justificadas em grande medida pelas mesmas razões que estão na origem da tese da sobredeterminação discursiva da sociologia. Por exemplo, já em 1928, na introdução a Contemporary Sociological Theories, Pitirim Sorokin lamentava a confusão entre teoria sociológica e teoria social e defendia que a teoria sociológica começava onde acabava a filosofia (Sorokin, 1928). ${ }^{6}$ A ausência, ainda hoje, da fronteira a que apelava Sorokin tem-se traduzido na manutenção da tendência para reproduzir, no ensino da teoria sociológica, e em particular nos manuais da disciplina, o estilo (também) predominantemente canónico do ensino da filosofia: um discurso organizado como narrativa historicamente sequencial sobre autores e escolas.

Aquele estilo prejudica o desenvolvimento da teoria sociológica, bem como da sociologia em geral, pelas razões já assinaladas há muito quer por Sorokin, quer por Merton. Mas prejudica, antes de mais, no domínio pedagógico, o ensino e aprendizagem da teoria sociológica nos planos motivacional, ético e instrumental.

No plano motivacional, porque retira interesse pelo estudo a boa parte dos alunos recém-chegados à universidade, confrontados, desde as primeiras aulas de teorias, com a apresentação dos contributos teórico-filosóficos de uns quantos barbudos, 
usando um vocabulário conceptual do século XIX, bem como referências às relações entre a obra desses barbudos e os contextos históricos em que viveram, de que é exemplo paradigmático a discussão sobre as relações entre as revoluções europeias de 1848 e as ideias dos pais fundadores da sociologia (Aron, 1967, pp. 253-281). Neste quadro, das duas uma, ou se transforma o ensino das teorias numa apresentação enciclopédica ligeira e caricatural da história da sociologia, ou se requer aos estudantes uma reflexão impossível sobre um domínio epistemológico que tem por objeto um conhecimento alargado das teorias sociológicas que, por definição, eles ainda não possuem.

No plano ético, porque a ligeireza inevitável com que são apresentadas as diferenças entre dezenas de autores e escolas, no tempo necessariamente comprimido de uma disciplina universitária semestral de licenciatura, implica a consolidação de a prioris sobre esses autores e escolas, em que o saber crítico se transmuta em julgamento sumário. Esta tendência é ainda reforçada pela variante negativa da fórmula canónica, a saber, a constituição de listas negras de autores que não merecem ser hoje estudados: por exemplo, Marx em escolas mais conservadoras, ou Parsons em escolas que confundem conservadorismo com crítica radical do marxismo. Deveria ser considerada eticamente inaceitável a realização daqueles julgamentos na base da ignorância, bem como a complacência, para dizer o menos, com a atitude de soberba com que se classifica e descarta sumariamente a obra de autores que consagraram a sua vida ao desenvolvimento da sociologia, publicando os resultados do seu trabalho e influenciando gerações de investigadores. Um bom professor de teorias sociológicas deveria começar por destacar, antes de mais, a possibilidade de encontrar contributos válidos e interessantes para o desenvolvimento da sociologia e da teoria sociológica em praticamente todos os textos-chave das diversas escolas do pensamento sociológico. O que, obviamente, não significa perder de vista a necessidade de dar a conhecer as clivagens reais e fundamentais que existem entre as principais escolas rivais no âmbito da teoria sociológica. Demasiado ecletismo, isto é, demasiada conciliação sem critério entre propostas diferentes pode ser, como argumenta Randall Collins, um obstáculo tão grande à cumulatividade no desenvolvimento da teoria sociológica como o fechamento dogmático, pois torna impossível a eliminação das teorias ou categorias teóricas que se revelaram erradas (Collins, 1999, p. 56).

Ou seja, mesmo enquanto apresentação de um cânone, o ensino da teoria sociológica como narrativa histórica do pensamento social, teórico-filosófico, acaba, em boa medida, por ser ineficaz. Porém, é no plano instrumental que mais se fazem sentir os efeitos negativos da opção pedagógica predominante. No final da narrativa estudada, o que é possível aos alunos aprender de relevante no plano especificamente teórico? Isto é, que domínios de conceptualização conhecem, que enunciados 
proposicionais sabem usar, em síntese, que explicações e modos de explicação aprenderam sobre os diferentes domínios da vida social? Mesmo no plano da relação com os clássicos, que "formulações mais antigas da teoria" aprenderam a utilizar e não apenas a julgar ou a celebrar (Merton, 1968, p. 50)?

A teoriaé para ser usada. Como argumenta Nicos Mouzelis, a teoria é uma caixa de ferramentas que usamos para construir, aplicar e melhorar explicações sobre o objeto da nossa disciplina, a vida social moderna (Mouzelis, 1995, p. 1). A teoria não é uma representação complexa impossível da complexidade da realidade (social), mas um conjunto de instrumentos conceptuais e proposicionais simples, abstratos e especializados que, usados, permitem explicar essa mesma realidade. Estudar teoria sociológica, nomeadamente nos primeiros anos de formação universitária, é, ou devia ser, aprender a reconhecer e a usar as várias caixas de ferramentas de que dispomos para conhecer e explicar a realidade social.

\section{A construção da sistemática e o lugar dos clássicos}

A defesa do ensino e estudo especializado da teoria sociológica, no sentido em que foi atrás definido, não implica, porém, a inutilidade do ensino e do estudo das ideias sociais. Uma reformulação do ensino de primeiro ciclo da fileira das disciplinas de teoria sociológica poderia incluir, a montante desta, a criação de uma disciplina semestral com esse objetivo e denominação. Porém, esse ensino e estudo não deveriam, em caso algum, fazer-se à custa do ensino e estudo da teoria sociológica propriamente dita, ou seja, do ensino e estudo da sua "sistemática atual" (Merton, 1968, p. 50). A organização curricular da fileira das disciplinas de teoria sociológica nas licenciaturas, no sentido mais específico do termo, deveria abandonar a apresentação histórica, sequencial, de autores e escolas. Faria mais sentido, valorizando sobretudo o estatuto instrumental da teoria, distinguir entre o estudo especializado dos diferentes níveis de organização dos padrões de relações sociais. Neste quadro, em vez de disciplinas sobre teorias clássicas e teorias contemporâneas, ou sobre clássicas, modernas e contemporâneas, quando a fileira é desdobrada em três cadeiras, teríamos disciplinas de microssociologia e de macrossociologia ou, sendo três as unidades curriculares, estas duas e uma terceira sobre mesossociologia. A primeira seria dedicada ao estudo dos processos e mecanismos de interação, a segunda ao estudo das estruturas e sistemas sociais e a terceira ao estudo dos grupos e dos processos e relações de agrupamento. ${ }^{7}$ Voltaremos, mais adiante, a esta proposta, concretizando um pouco mais o que poderiam ser as linhas programáticas gerais de cada uma daquelas disciplinas. 
É verdade que organizar esta sequência de disciplinas de teorias sociológicas esbarraria com uma primeira dificuldade óbvia. Os textos de síntese disponíveis sobre teorias sociológicas estão, em geral, organizados segundo a forma canónica, mesmo quando o seu objetivo é mais teórico do que pedagógico. Ou seja, faltam, como no tempo de Merton, trabalhos de síntese, com ou sem objetivos pedagógicos, sobre a "sistematicidade atual" da teoria sociológica, ${ }^{8}$ textos necessários como suporte pedagógico no ensino da teoria sociológica. Estamos, assim, presos na armadilha perfeita. Não socializamos as novas gerações de sociólogos com base num programa de sociologia científica e, por isso, sociólogos socializados na fórmula canónica reproduzem, no seu trabalho de desenvolvimento da sociologia, essa mesma fórmula canónica, concretizando-se, a passo de caracol, o desenvolvimento da "sistemática da teoria". A profecia cumpre-se, justifica-se, a si própria: a sociologia é sobrediscursivamente determinada e, por isso, deve ser como tal ensinada. Como tal ensinada, dificulta a emergência do programa alternativo da sociologia científica que fica sem grupos veiculares ("carrier groups"). Como se sabe, porém, a injeção de reflexividade nestas dinâmicas de autorreforço permite a sua interrupção.

A sociologia, insiste-se, pode ser desenvolvida como ciência, o que inclui a construção, por confronto crítico e acumulação, de teorias sociológicas permanentemente aperfeiçoadas e ampliadas que sustentem a construção de explicações sobre diferentes domínios analíticos ou categorias de fenómenos sociais. Este programa será mais fácil se, no domínio da construção da teoria, forem garantidas critérios de abstratização, simplicidade e multidimensionalidade como se argumentou noutro texto (Pires, 2014). E poderá ser desenvolvido sistematicamente de modo alargado se os seus resultados constituírem objeto de formação de novas gerações de sociólogos.

A relação com os autores e as escolas não desaparece neste processo pois é através do confronto crítico dos contributos plurais de diferentes autores e escolas teóricas que poderá emergir uma "sistemática atual" da teoria. Sistemática que deverá incorporar a inevitabilidade da existência de zonas de ausência ou rarefação de teorização, de outras de persistência de controvérsia e, ainda, de défices de articulação entre os seus componentes. Uma "sistemática atual" da sociologia não deve ser entendida como objeto teórico desejavelmente perfeito, acabado ou autossustentado, protegido da crítica por forte carapaça retórica. Pelo contrário, a vulnerabilidade da teoria à crítica é uma boa notícia, pois é no confronto com as consequências dessas vulnerabilidades que se fará o seu desenvolvimento, sobretudo quando tais vulnerabilidades forem, antes de mais, vulnerabilidades ao escrutínio lógico dos seus enunciados e aos resultados do trabalho empírico que ela, teoria, comanda. Uma boa teoria não deve ser à prova dos factos, antes deve ser 
entendida como componente do trabalho científico, a par do trabalho empírico de investigação, e desenhada para poder ser vulnerável, isto é, questionável pelos resultados daquele trabalho de investigação. A contrario, Carlo M. Cipolla dá-nos um belo exemplo caricatural de como construir uma axiomática à prova de factos quando começa a exposição das suas leis sobre a estupidez humana com o enunciado "cada um de nós subestima sempre e inevitavelmente o número de indivíduos estúpidos em circulação" (Cipolla, 1988, p. 49). Obviamente, com este ponto de partida, todas as objeções empíricas aos enunciados que se seguem podem ser descartadas com facilidade invocando a subestimação estabelecida na primeira lei.

Umberto Eco dizia que o estatuto ideológico das ideologias resultava da universalização do particular que estas operavam (Eco, 1973, pp. 222-3). Boa parte do estatuto controverso das teorias sociológicas rivais que hoje são apresentadas como mutuamente exclusivas aos estudantes, e aos sociólogos em geral, tem origem em operação semelhante de universalização do particular. A construção da "sistemática atual" da teoria será por isso mais rica, ainda que incompleta e imperfeita, como acima referido, se não deitar fora a criança com a água do banho e souber isolar o que de particular, mas abstrato e válido, tem cada teoria e reconstruir muitas das oposições entre esses contributos particulares como dimensões teóricas eventualmente complementares nos planos analítico, conceptual e proposicional. ${ }^{9}$

É o estudo da sistemática da teoria sociológica, assim definida, incompatível com o estudo dos clássicos, "antigos" ou "modernos"? Com o estudo das obras de Marx, Durkheim e Weber, ou de Parsons, Goffman e Coleman, ou mesmo de Bourdieu e Giddens, apenas a título de exemplo? De forma alguma. Como salienta Stinchcombe, em artigo sugestivamente intitulado "Should sociologists forget their mothers and fathers" (1982), o estudo dos clássicos contribui para a formação dos sociólogos na medida em que permite o acesso a uma reserva de ideias e sugestões e a modos de argumentação sofisticados, sendo ainda fonte frequente de inspiração em processos de inovação. Em rigor, atribuímos o estatuto de clássicos a obras e autores cujo estudo tem, duradouramente, aqueles efeitos..$^{10}$

Stinchcombe conclui, portanto, que faz sentido estudar os clássicos, ou melhor, as obras dos clássicos, integrais e não em excertos selecionados, pois é a riqueza dessas obras, na sua plenitude, muitas vezes marcadas por dúvidas e inconsistências inspiradoras, que está na origem dos efeitos atrás assinalados. Faz sentido, citemos, porque "os estudantes em níveis avançados precisam de algo mais complicado do que os clichês dos livros didáticos do ensino fundamental, se queremos persuadi-los a tornar as suas mentes mais complexas" (Stinchcombe, 1982, p. 2; itálicos acrescentados). Sublinhamos a expressão níveis "avançados", noutras partes do artigo de Stinchcombe substituída por alunos "pós-graduados", porque 
Tabela 1 Disciplinas de teorias sociológicas nas licenciaturas de sociologia das universidades públicas portuguesas, $2019 / 20$

\begin{tabular}{|c|c|c|}
\hline Universidade & Número & Designação \\
\hline Iscte, Instituto Universitário de Lisboa & 3 & $\begin{array}{l}\text { Teorias sociológicas clássicas } \\
\text { Teorias sociológicas: grandes escolas } \\
\text { Teorias sociológicas contemporâneas }\end{array}$ \\
\hline Universidade dos Açores & 2 & $\begin{array}{l}\text { Teorias sociológicas clássicas } \\
\text { Teorias sociológicas contemporâneas }\end{array}$ \\
\hline Universidade do Algarve & 4 & $\begin{array}{l}\text { Teorias clássicas I } \\
\text { Teorias clássicas II } \\
\text { Teorias contemporâneas I } \\
\text { Teorias contemporâneas II }\end{array}$ \\
\hline Universidade da Beira Interior & 3 & $\begin{array}{l}\text { Teorias sociológicas: fundadores e clássicos } \\
\text { Teorias sociológicas modernas } \\
\text { Teorias sociológicas contemporâneas }\end{array}$ \\
\hline Universidade de Coimbra & 2 & $\begin{array}{l}\text { Pensamento sociológico clássico } \\
\text { Teorias sociológicas }\end{array}$ \\
\hline Universidade de Évora & 2 & $\begin{array}{l}\text { Teorias sociológicas I } \\
\text { Teorias sociológicas II }\end{array}$ \\
\hline Universidade de Lisboa & 2 & $\begin{array}{l}\text { Teorias sociológicas clássicas } \\
\text { Teorias sociológicas contemporâneas }\end{array}$ \\
\hline Universidade do Minho & 3 & $\begin{array}{l}\text { Teorias sociológicas I } \\
\text { Teorias sociológicas II } \\
\text { Teorias sociológicas III }\end{array}$ \\
\hline Universidade Nova de Lisboa & $\begin{array}{c}2 \\
\text { (obrigatórias) } \\
4 \\
\text { (optativas, } \\
\text { ramo de teorias) }\end{array}$ & $\begin{array}{l}\text { Sociologia geral: fundamentos } \\
\text { Sociologia geral: teorias } \\
\text { Teorias sociológicas: os fundadores } \\
\text { Teorias sociológicas contemporâneas } \\
\text { Teorias da ação social } \\
\text { Comunidades e dinâmicas sociais }\end{array}$ \\
\hline Universidade do Porto & 4 & $\begin{array}{l}\text { Teorias sociológicas I } \\
\text { Teorias sociológicas II } \\
\text { Correntes atuais da sociologia I } \\
\text { Correntes atuais da sociologia II }\end{array}$ \\
\hline
\end{tabular}

Nota: disciplinas obrigatórias, exceto quando indicado outro estatuto

Fonte: páginas Web das universidades (consultadas em 16 de dezembro de 2019).

sem esta não se percebe o argumento, que subscrevemos, de Stinchcombe. No artigo que temos vindo a referir, o que se discute é o estudo das obras dos clássicos nos níveis pós-graduados de ensino, e não em toda a fileira universitária. O estudo dos clássicos não é o modo de aceder, em termos introdutórios, na formação de primeiro ciclo, de licenciatura, às teorias sociológicas, mas o modo de desenvolver, em níveis pós-graduados, de mestrado e de doutoramento, a capacidade de utilização não rotineira do conhecimento já adquirido naquele domínio. É pois nos níveis avançados de formação que se deve incluir o estudo das principais obras dos "clássicos", no sentido estatutário e não cronológico do termo. Ou seja, o estudo dos 
clássicos deve ser antecedido do estudo da sistemática da teoria, não o contrário.

Infelizmente, o que ainda hoje predomina nos cursos de sociologia, por todo o mundo, mais de 70 anos depois das queixas de Merton, é, como já se disse, a fórmula canónica enquanto modo introdutório de ensino da teoria sociológica, que prepara mal para o estudo aprofundado das obras dos clássicos nos níveis pós-graduados. Esta é, também, a regra em Portugal, com a exceção parcial da licenciatura de sociologia da Universidade Nova de Lisboa (ver tabela 1). De resto, nas outras nove licenciaturas existentes nas universidades públicas do país, o que é fundamentalmente diferente é o número de cadeiras em que se desdobra o ensino canónico da teoria sociológica: duas cadeiras, uma sobre os clássicos e outras sobre os contemporâneos, em quatro das nove licenciaturas (nas universidades dos Açores, Coimbra, Évora e Lisboa); três cadeiras, sobre os clássicos, os modernos e os contemporâneos em três outras licenciaturas (no Iscte e nas universidades da Beira Interior e do Minho); e quatro cadeiras, duas sobre os clássicos e duas sobre os modernos, em duas licenciaturas (nas universidades do Algarve e do Porto).

Seguindo o modelo canónico, o desdobramento na maioria dos casos em três ou mesmo quatro disciplinas, e não em duas (clássicos/contemporâneos), atenua alguns dos efeitos do que Abrutyn (2013) designou por "trituração de tempo": ou seja, a impossibilidade de comprimir, sem perdas de contributos importantes, a narrativa cronológica em que se transformou o ensino da teoria sociológica. A sistemática continua ignorada mas a tendência para a excessiva simplificação da história da disciplina é atenuada, sobretudo quando não se aproveita mais tempo letivo para apresentar mais autores (o que às vezes acontece). Atenua mas não elimina. Como não resolve o problema da sequência do estudo das teorias nos diferentes níveis de ensino, graduado e pós-graduado. Vejamos mais em pormenor, a título de exemplo, como estes problemas se manifestam no ensino e estudo das teorias sociológicas no Iscte, ao longo dos três ciclos de formação: licenciatura, mestrado e doutoramento.

Na licenciatura, há três disciplinas, nos três primeiros semestres, em que são apresentados, por ordem tendencialmente cronológica, os principais autores e correntes das teorias sociológicas. No primeiro semestre, os clássicos, no segundo o que poderemos designar como os modernos e, no terceiro, os contemporâneos. Os problemas de "trituração de tempo" manifestam-se logo na primeira daquelas disciplinas. Nas teorias sociológicas clássicas, o essencial do tempo letivo é ocupado, e bem, se adotarmos a forma canónica, com o estudo de Marx, Durkheim e Weber, antecedido de uma referência a alguns dos contributos de Comte e Spencer. Do programa constam ainda duas aulas finais sobre Simmel que, no entanto, em vários anos não são lecionadas por impossibilidade de cumprir a compressão prevista 
na exposição sobre os três autores principais (Marx, Durkheim e Weber). No ensino programado sobre Durkheim está prevista, mas frequentemente não é lecionada, pelas mesmas razões, uma aula final sobre religião e rituais, organizada em torno dos contributos de As Formas Elementares da Vida Religiosa (1912).

Esta última perda é elucidativa dos problemas de seletividade e simplificação que decorrem da "trituração do tempo" assinalada por Abrutyn e que resultam da opção pela modalidade canónica de ensino das teorias, não de qualquer falha de desempenho na sua concretização (bem pelo contrário). Sem referência ao Durkheim de As Formas Elementares da Vida Religiosa ficamos com o conhecido afunilamento dos contributos do autor que sustenta a sua apresentação como o percursor fundacional do funcionalismo parsoniano, e tão só. No entanto, os estudos de Durkheim sobre a religião, bem como sobre os sistemas de classificação (com Marcel Mauss), devem ser referenciados como uma das origens do interacionismo norte-americano. Como, por exemplo, é assinalado na obra de Collins sobre a história da teoria sociológica, Four Sociological Traditions (1994), em que o capítulo sobre Durkheim é desdobrado em duas secções principais: uma sobre a tradição macrossociológica (funcionalista) e outra sobre a antropologia social e a microssociologia norte-americana. Sem ter em consideração esta genealogia, bem como os contributos de Simmel, constrói-se, posteriormente, uma história do interacionismo em que Mead e o pragmatismo filosófico de Peirce e James ganham uma influência desmesurada e fica incompreensível, por exemplo, a centralidade do conceito de ritual em Goffman (e no próprio Collins). Em rigor, fica mesmo na sombra a forte costela durkheimiana, para dizer o mínimo, de Goffman e uma das razões por que tantos autores se recusam a subsumir a "perspetiva dramatúrgica" no interacionismo simbólico (por exemplo, Turner, 2013). Falha que, paradoxalmente, resulta da procura de limitação dos efeitos mais perversos, porque simplificadores, da lógica canónica, presentes sobretudo quando se multiplicam os autores estudados. Sendo que reduzir o número dos autores e obras a estudar substitui os efeitos da simplificação caricatural pelos da ortodoxia induzida pela seletividade.

Este tipo de problemas é, como se disse, inevitável quando se escolhe a narrativa cronológica, canónica, como princípio organizador do ensino das teorias sociológicas. É, ainda, essa mesma escolha que explica a existência de gerações de sociólogos perdidos, nomeadamente entre os clássicos e Parsons. No artigo de Abrutyn, já citado, é compilada uma lista dos sociólogos perdidos que inclui, entre outros, boa parte dos autores da chamada Escola de Chicago (Abrutyn, 2013, pp. 136-8), a que poderíamos acrescentar, apenas a título de exemplo, Maurice Halbwachs, em França, ou, um pouco mais tarde, Norbert Elias, primeiro na 
Alemanha e depois no Reino Unido. Dir-se-á que problemas de seletividade existirão qualquer que seja o modo de ensinar a teoria sociológica. É verdade, mas num ensino organizado na base de domínios analíticos é mais fácil garantir a presença dos principais conceitos e teorias. Dito de outro modo, a sistemática permite uma compactação maior com menos perdas do que a narrativa histórica em torno dos protagonistas das teorias. A sistemática pode e deve ser simples, a narrativa histórica ou é complexa ou perde os efeitos que procura e a podem justificar.

Continuando a exemplificação. No currículo do doutoramento do Iscte estão incluídas duas disciplinas dedicadas ao estudo de grandes obras teóricas, clássicas e contemporâneas, o que, no plano formal, converge com os argumentos de Stinchcombe sobre o lugar dos "clássicos", no sentido reputacional do termo. No meio, no mestrado, existe uma cadeira de teorias sociológicas, no segundo semestre do primeiro ano: Debates Contemporâneos em Teorias Sociológicas. Trata-se, no atual plano de estudos, de uma disciplina opcional que integra, com a disciplina Epistemologia e Sociologia, o ramo "investigação" do mestrado.

Entre a narrativa cronológica da licenciatura e o estudo das grandes obras clássicas no doutoramento, que lugar ocupa esta disciplina de mestrado? Claramente, o de ocupar o vazio resultante da ausência prévia, na licenciatura, de espaços de estudo da "sistemática" da teoria. Dispondo apenas de um semestre para o efeito, deslocou-se, porém, o efeito de "trituração do tempo", assinalado por Abrutyn, da narrativa canónica para a sistemática à Merton. Para limitar as consequências dessa "trituração", aquela sistemática é apenas introduzida com o estudo das principais categorias conceptuais constitutivas dos três níveis de organização dos sistemas sociais - o micro, o macro e o meso - através de um programa dividido em três partes, em torno dos conceitos de ação social, estrutura social e poder social, respetivamente. E assim se corre o risco de induzir uma representação da teoria enquanto sistema analítico, como sistemática de conceitos (Turner, 2013, pp. 849-851), fazendo desaparecer toda a sua componente proposicional, de que os conceitos são peças mas não substitutos.

Há, nesta sequência, vários problemas. Em primeiro lugar, falta densidade no estudo da sistemática da teoria, ausente na formação da licenciatura. Em segundo lugar, o estudo das grandes obras dos clássicos "antigos" e contemporâneos, que deveria ser um momento de aprofundamento no estudo da teoria, é feito por alunos que, em regra, não estudaram nem a sistemática nem o cânone da teoria, pois só são obrigados a frequentar integralmente a parte escolar do doutoramento, e bem, aqueles doutorandos que não têm formação prévia em sociologia. ${ }^{11} \mathrm{~A}$ boa solução para todos estes problemas passaria por: 
- na licenciatura, centrar o ensino e estudo das teorias sociológicas no plano da sistemática e não na história da teoria;

- nos níveis pós-graduados, voltar a fundir as componentes escolares de mestrado e doutoramento o que, no caso do ensino das teorias sociológicas, permitiria que todos os estudantes nestes níveis mais avançados estudassem, numa lógica de aprofundamento, as grandes obras que a integram a sua história.

\section{O ensino da sistemática: esboço de linhas programáticas}

Na proposta que se faz neste artigo, a questão verdadeiramente nova é a elaboração de um programa de ensino e estudo da teoria sociológica na licenciatura, em moldes não canónicos. Como atrás se referiu, esse programa ganharia em ter como objeto a sistemática da teoria e ser desdobrado em três disciplinas semestrais sobre a micro, macro e meso sociologia, preferencialmente por esta ordem. Examinemos cada uma das componentes desta proposta.

A sistemática poderia ser organizada a partir de um núcleo problemático comum a desdobrar nas suas múltiplas concretizações em cada uma das disciplinas. Como já defendi noutros textos (Pires, 2012), pelo que me dispenso de retomar os argumentos aí apresentados, proponho, na sequência de autores como Alexander (1988) e Giddens (1984), mas também de Parsons (1937) e Goffman (1983), que esse núcleo seja constituído em torno da explicação da ordem social, definida como ordem factual, isto é, como o resultado da padronização do mundo social, como o oposto de caos (mas não de conflito, uma dinâmica social também padronizada). Explicação que se desdobra na resposta a duas perguntas fundamentais. Primeira, como se explica a emergência de padrões ordenados de atos e relacionamentos protagonizados por indivíduos em abstrato autónomos, criativos e livres? E, segunda, que consequências têm sobre esses indivíduos aqueles padrões de atos e relacionamentos que se constituem, por sua vez, em contextos, meios e constrangimentos da sua ação.

O desdobramento proposto, em três disciplinas, retém o modelo analítico apresentado noutro texto (Pires, 2014). Aí se argumenta que micro, meso e macro constituem "níveis de integração das relações sociais" (Costa, 1999, p. 490) com propriedades específicas, pelo que a distinção entre eles é não só analítica como ontológica (admitindo-se que a segunda parte da afirmação é mais controversa mas irrelevante para o que a seguir se propõe). Ceada um desses níveis é composto por tipos diferentes de padrões ordenados de relações sociais: relações de interação, no nível micro, relações de agrupamento e relações ntre grupos, no nível meso, e relações 
de interdependência sistémica, no nível macro. Estas relações podem ser resumidamente definidas como, respetivamente, relações intersubjetivas e entre atos individuais (micro), relações de agrupamento e relações entre esses agrupamentos, ou seja, relações entre relações (meso), e, por fim, relações entre propriedades das relações entre pessoas e entre grupos (macro). ${ }^{12}$

No ensino e estudo destes níveis, cada um correspondente a uma disciplina, a organização da sistemática defendida por Merton poderia ser feita, numa lógica de reconstrução multidimensional do pluralismo da teoria (Berthelot, 2001), através da síntese cumulativa do património sociológico com base em critérios que evitem o ecletismo improdutivo criticado por Collins e já atrás referido. Um primeiro critério que cumpre esse objetivo e é há muito usado, explícita ou implicitamente, na conceptualização sociológica, é o que distingue, analiticamente, as dimensões instrumentais e simbólicas da vida social, também muitas vezes referidas como materiais e ideacionais. São, obviamente, dimensões complementares de análise e não mutuamente exclusivas. Até porque, no plano empírico, o que encontramos são realidades constituídas em termos instrumentais e simbólicos, mesmo que em proporção variável. Como refere Nicos Mouzelis, todos os sistemas sociais são complexos de posições e normas (Mouzelis, 2008, pp. 98-99), complexos que constituem uma das especificações da multidimensionalidade daquelas realidades.

Muitas das oposições antigas construídas com base nas categorias usadas para especificar as dimensões instrumentais e simbólicas diziam respeito mais à sua eventual hierarquização em processos de articulação teórica do que a qualquer reivindicação de exclusividade. Se resistirmos à clássica oposição entre materialismo e idealismo, como modos de explicação concorrentes da vida social, será possível identificar as diferentes dimensões instrumentais e simbólicas dos processos de interação, de estruturação e de agrupamento sem qualquer apriorismo sobre a sua relação mútua, provavelmente variável em função do objeto de análise em causa.

Num primeiro nível de desdobramento analítico dos níveis micro, macro e meso, seria assim possível distinguir entre:

- $\quad$ interação instrumental e interação simbólica, no nível micro;

- estruturas materiais e estruturas culturais, no nível macro;

- círculos relacionais e círculos normativos, no nível meso.13

Os seis espaços teóricos identificados desta forma compõem um esquema analítico parcialmente convergente com o apresentado por Jonathan $\mathrm{H}$. Turner no primeiro volume de Theoretical Principles of Sociology (Turner, 2010a, pp. 12-20). Num momento posterior, aqueles seis espaços poderiam ainda ser sucessivamente desdobrados, em 
termos sistemáticos, ainda que desigualmente especificados, de acordo com os desenvolvimentos teóricos que marcaram a história da teoria sociológica. Por exemplo, no estudo da interação instrumental, poderiam ser estudadas a racionalidade da ação e as trocas sociais, enquanto o estudo da interação simbólica poderia incluir o estudo dos processos de interpretação comunicacional, por um lado, e de interpretação normativa, por outro. O estudo das estruturas materiais poderia incluir um capítulo sobre as estruturas morfológicas e outro sobre as estruturas da desigualdade, enquanto o estudo das estruturas culturais seria desdobrado no estudo das instituições e no estudo das estruturas de significação. Por fim, o estudo do nível meso poderia incluir secções sobre o estudo de círculos relacionais e o estudo de círculos normativos, em termos abstratos gerais e na sua concretização enquanto redes, grupos e organizações.

Um segundo nível de especificação deveria incluir a análise dos principais modos de causalidade operantes nas relações entre os três níveis (Pires, 2014). Deste modo, o estudo do nível micro incluiria uma seç̧ão sobre processos de causalidade generativa e de agregação, o estudo do nível macro uma seç̧ão sobre processos de causalidade potencial, por condicionamento e orientação da ação via socialização/incorporação, e, por fim, o estudo do nível meso incluiria uma secção sobre o poder social, pois é neste nível que são estabilizadas, através de processos relacionais e normativos de agrupamento, as relações de poder estruturalmente suportadas e interactivamente ativadas.

Por fim, uma curta justificação sobre a ordem expositiva proposta: microssociologia, macrossociologia e mesossociologia. A preferência por esta sequência tem fundamentos exclusivamente pedagógicos. A colocação da disciplina de mesossociologia no final da fileira é a mais fácil de justificar: boa parte dos fenómenos de agrupamento social que constituem o seu objeto envolvem efeitos e articulações de processos micro e macrossociológicos que convém conhecer previamente. Há, hoje, algum consenso sobre esta solução, adotada, entre outros autores, por Jonathan Turner nos seus Theoretical Principles of Sociology, atrás referidos. Já a ponderação da sequência inicial, micro-macro ou macro-micro, é mais controversa. Naquela obra de Turner, o primeiro volume é sobre a macrossociologia, uma sequência oposta, portanto, à que se propõe neste texto. Penso, porém, que a sequência inversa, micro-macro, permite contrariar melhor a tendência dominante entre estudantes de sociologia (e não só entre estudantes) para a antropomorfização das categorias sociológicas, em particular das que têm como referente o universo macrossocial. Ou seja, de atribuição de propriedades dos atores e das relações entre atores aos sistemas e às relações sistémicas, na base de uma adesão convicta ao que poderíamos designar como sociologia Walt Disney, a qual tem "a sedução das falsas explicações fáceis" (Pires, 2015, p. 127). 
Em resumo, as linhas programáticas das três disciplinas em que propomos dividir a sistematização e estudo das teorias sociológicas podem ser esboçadas nos seguintes termos:

\section{Teorias Sociológicas I: Microssociologia}

I.1 Interação instrumental

I.2 Interação simbólica

I.3 Processos de agregação

\section{Teorias sociológicas II: Macrossociologia}

II.1 Estruturas materiais

II.2 Estruturas culturais

II.3 Processos de estruturação

\section{Teorias Sociológicas III: Mesossociologia}

III.1 Círculos relacionais

III.2 Círculos normativos

III.3 Processos de poder

Esta proposta tem, evidentemente, um estatuto exploratório. O seu objetivo principal é, sobretudo, o de demonstrar a possibilidade de concretização da ideia de organização do ensino e estudo da sistemática da teoria sociológica em substituição da fórmula canónica há muito tempo praticada. Proposta que, a concretizar-se, terá, pelo menos, a vantagem de assegurar o conhecimento teórico dos principais domínios analíticos e conceptuais da sociologia.

\section{Notas}

O autor escreve segundo as regras do novo acordo ortográfico.

1 Simpósio da Escola de Sociologia e Políticas Públicas: o Ensino das Teorias Sociológicas em Debate, Iscte, Lisboa, 28 de maio de 2018.

2 A falta de questionamento não é um exclusivo português. Numa pesquisa sobre o tema nos números dos últimos dez anos da revista da Associação Americana de Sociologia dedicada ao ensino da sociologia (Teaching Sociology), os artigos sobre teorias sociológicas encontrados incidiam sobre a didática do seu ensino não sobre a natureza das teorias sociológicas e as concepções divergentes sobre o seu ensino.

3 Ver, por exemplo, as referências a Ibn-Khaldun e Du Bois no manual de Ritzer e Stepnisky (2017). Ainda a título de exemplo, Ibn-Khaldun é um dos autores tratados na 
disciplina de teorias clássicas na universidade de Lahore (Paquistão), a par de Hobbes, Rousseau, Comte, Montesquieu, Marx, Weber e Durkheim (Barbalet, 2013). Na Universidade da Califórnia, Berkeley, a disciplina Sociological Theory I é dedicada ao estudo de Marx, Weber, Durkheim e Du Bois [https://sociology.berkeley.edu/sites/default/files/documents/syllabi/sp17/soc101\%20sp\%20muller.pdf].

Para uma reflexão, com conclusão diversa da de David Parker, veja-se o interessante artigo de Jack Barbalet (2013) sobre a sua experiência de ensino de teorias sociológicas clássicas numa universidade de Hong Kong, com um programa centrado, exclusivamente, no estudo das obras de Marx, Durkheim, Weber e Simmel.

5 Ver, por exemplo, a inclusão de Mead e Parsons nos clássicos em George Ritzer (Ed.) (2003). The Blackwell companion to major classical social theorists, a par dos mais canónicos Comte, Spencer, Marx, Durkheim, Weber e Simmel, e dos novos canonizados Charlotte Perkins Gilman, Harriet Martineau e W.E.B. Du Bois (e ainda Alfred Schutz).

6 Para uma defesa similar, contemporânea, da distinção entre teoria social e teoria sociológica, ver Jonathan Turner (1985), mas também Nicos Mouzelis (1991, 1995).

7 Para um proposta de organização da fileira das disciplinas de teoria sociológica no ensino da sociologia ao nível das licenciaturas convergente com esta, ver Abrutyn (2013).

8 A principal exceção na literatura sobre teoria sociológica é a obra de Jonathan Turner, em três volumes, intitulada Theoretical Principles of Sociology (2010-2012). Num plano mais sintético, merece destaque o livro de John Scott (2011). Conceptualising the social world: Principles of sociological analysis. No plano pedagógico, uma organização da exposição da teoria com base em domínios conceptuais em lugar de autores ou escolas está ainda presente no livro de Malcolm Waters (1994). Modern sociological theory.

9 Ver, para uma ilustração do trabalho de especificação da validade particular de teorias (substantivas) com pretensões de generalidade, a crítica de Raymond Boudon às teorias do desenvolvimento em O lugar da desordem (1984). Para um ensaio de reconversão de oposições teóricas em dimensões analíticas complementares, no plano conceptual, ver Pires (2007).

10 Não adquirem o estatuto de clássicos a maioria dos autores reputados no seu tempo: consulte-se, por exemplo, o índice do livro de Sorokin, de 1928, sobre teorias sociológicas contemporâneas, e admita-se que, pura e simplesmente, não temos qualquer ideia sobre quem são boa parte dos autores aí citados (e de muitos outros teremos, provavelmente, apenas uma ligeira informação).

11 Esta solução não é partilhada pela maioria dos programas doutorais em sociologia existentes no país que seguem, mais frequentemente, a nova tradição de escolarização (absurda, a meu ver) dos doutoramentos.

12 Ver a argumentação convergente com esta apresentada recentemente por Turner (2010a, 2010b, 2012), bem como, em obras hoje já a caminho do estatuto de clássicas, teorizações semelhantes feitas por Luhmann (1982) e Archer (1995). 
13 Se o estudo dos processos sociais de âmbito meso tem uma longa história na teoria sociológica, de que são exemplares os trabalhos de Robert K. Merton (1968), a sua sistemática é mais difícil de construir do que no caso dos domínios da interação e das estruturas, até por falta de um vocabulário estabilizado. Os conceitos de círculos relacionais e círculos normativos retêm, adaptando-as, as propostas de Elder-Vass (2010), a sua genealogia nas obras de Georg Simmel (1908) e Norbert Elias (1970), bem como o vocabulário proposto por López e Scott (2000) quando distinguem entre estrutura relacional e estrutura institucional.

\section{Referências}

Abrutyn, S. (2013). Teaching sociological theory for a new century: Contending with the time crunch. The American Sociologist, 44(2), 132-154. doi: 10.1007/s12108-013-9181-x

Alexander, J. C. (1987). The centrality of the classics. Em A. Giddens, \& J. H. Turner (Eds.). Social theory today (pp. 11-57). Cambridge: Polity Press.

Alexander, J. C. (1988). The new theoretical movement. Em N. J. Smelser (Ed.), Handbook of sociology (pp. 77-101). Londres: Sage.

Archer, M. S. (1995). Realist social theory: The morphogenetic approach. Cambridge: Cambridge University Press.

Aron, R. (1982 [1967]). As etapas do pensamento sociológico. São Paulo: Martins Fontes.

Barbalet, J. M. (2013). Teaching classical sociological theory in Hong Kong SAR China. Journal of Sociology, 49(4), 426-40. doi: 10.1177/1440783313504054

Berthelot, J.-M. (2001). Programmes, paradigmes, disciplines: Pluralité et unité des sciences sociales. Em J.-M. Berthelot (Ed.), Épistémologie des sciences sociales (pp. 457-519). Paris: PUF.

Boudon, R. (1990 [1984]). O lugar da desordem: Crítica das teorias da mudança social. Lisboa: Gradiva.

Cipolla, C. M. (1993 [1988]). Allegro ma non troppo. Oeiras: Celta.

Collins, R. (1994). Four sociological traditions. Oxford: Oxford University Press.

Collins, R. (1999). Socially unrecognized cumulation. The American Sociologist, 30(2), 41-61. Disponível em https://www.jstor.org/stable/27698911

Costa, A. F. (1999). Sociedade de bairro: Dinâmicas sociais da identidade cultural. Oeiras: Celta.

Durkheim, E. (2002 [1912]). As formas elementares da vida religiosa: O sistema totémico na Austrália. Oeiras: Celta.

Eco, U. (1977 [1973]). O signo. Lisboa: Presença.

Elder-Vass, D. (2010). The causal power of social structures: Emergence, structure and agency. Cambridge: Cambridge University Press.

Elias, N. (1980 [1970]). Introdução à sociologia. Lisboa: Edições 70.

Giddens, A. (1984). The constitution of society: Outline of the theory of structuration. Cambridge: Polity. 
Giddens, A. (1992 [1989]). As consequências da modernidade. Oeiras: Celta.

Goffman, E. (1983). The interaction order. American Sociological Review, 48(1), 1-17. Disponível em https:/ / www.jstor.org/stable/2095141

López, J., \& Scott, J. (2000). Social structure. Buckingham: Open University Press.

Luhmann, N. (1982). The differentiation of society. Nova Iorque: Columbia University Press.

Merton, R. K. (1968, 1970). Sociologia: Teoria e estrutura (3 $3^{\text {a }}$ ed.) (revista e aumentada). São Paulo: Editora Mestre Jou.

Mouzelis, N. (1991). Back to sociological theory: The construction of social orders. Londres: Macmillan.

Mouzelis, N. (1995). Sociological theory: What went wrong? Diagnosis and remedies. Londres: Routledge.

Mouzelis, N. P. (2008). Modern and postmodern social theorizing: Bridging the divide. Cambridge: Cambridge University Press.

Parker, D. (1997). Viewpoint: Why bother with Durkheim? Teaching sociology in the 1990s. The Sociological Review, 45(1), 122-146. doi: 10.1111/1467-954X.00057

Parsons, T. (1937). The structure of social action. Nova Iorque: The Free Press.

Pires, R. P. (2007). Árvores conceptuais: Uma reconstrução multidimensional dos conceitos de ação e de estrutura. Sociologia, Problemas e Práticas, 53, 11-50. Disponível em http://www.scielo.mec.pt/scielo.php?script=sci_arttext\&pid= S0873-65292007000100002\&lng=pt\&nrm=iso

Pires, R. P. (2012). O problema da ordem. Sociologia, Problemas e Práticas, 69, 31-46. doi: 10.7458/SPP201269785

Pires, R. P. (2015). Modelo teórico de análise sociológica. Sociologia, Problemas e Práticas, 74, 31-50. doi: 10.7458/SPP2014743199

Ritzer, G. (Ed.) (2003). The Blackwell companion to major classical social theorists. Oxford: Blackwell.

Ritzer, G., \& Stepnisky, J. (2017). Sociological theory (10ª ed.). Los Angeles: Sage.

Scott, J. (2011). Conceptualising the social world: Principles of sociological analysis. Cambridge: Cambridge University Press.

Simmel, G. (1999 [1908]). Sociologie: Études sur les formes de la socialisation. Paris: PUF.

Sorokin, P. (1928). Contemporary sociological theories. Nova Iorque: Harper \& Brothers.

Stinchcombe, A. L. (1982). Should sociologists forget their mothers and fathers?. The American Sociologist, 17(1), 2-11. Disponível em https:/ / www.jstor.org/stable/27702490

Turner, J. H. (1985). In defense of positivism. Sociological Theory, 3(2), 24-30.

Turner, J. H. (2010a). Theoretical principles of sociology (vol. I): Macrodynamics. Nova Iorque: Springer.

Turner, J. H. (2010b). Theoretical principles of sociology (vol. II): Microdynamics. Nova Iorque: Springer.

Turner, J. H. (2012). Theoretical principles of sociology (vol. III): Mesodynamics. Nova Iorque: Springer. 
Turner, J. H. (2013). Theoretical sociology: 1830 to the present. Newbury Park (CA): Sage. Waters, M. (1994). Modern sociological theory. Londres: Sage.

Data de submissão: 06/01/2020 | Data de aceitação: 19/03/2020 